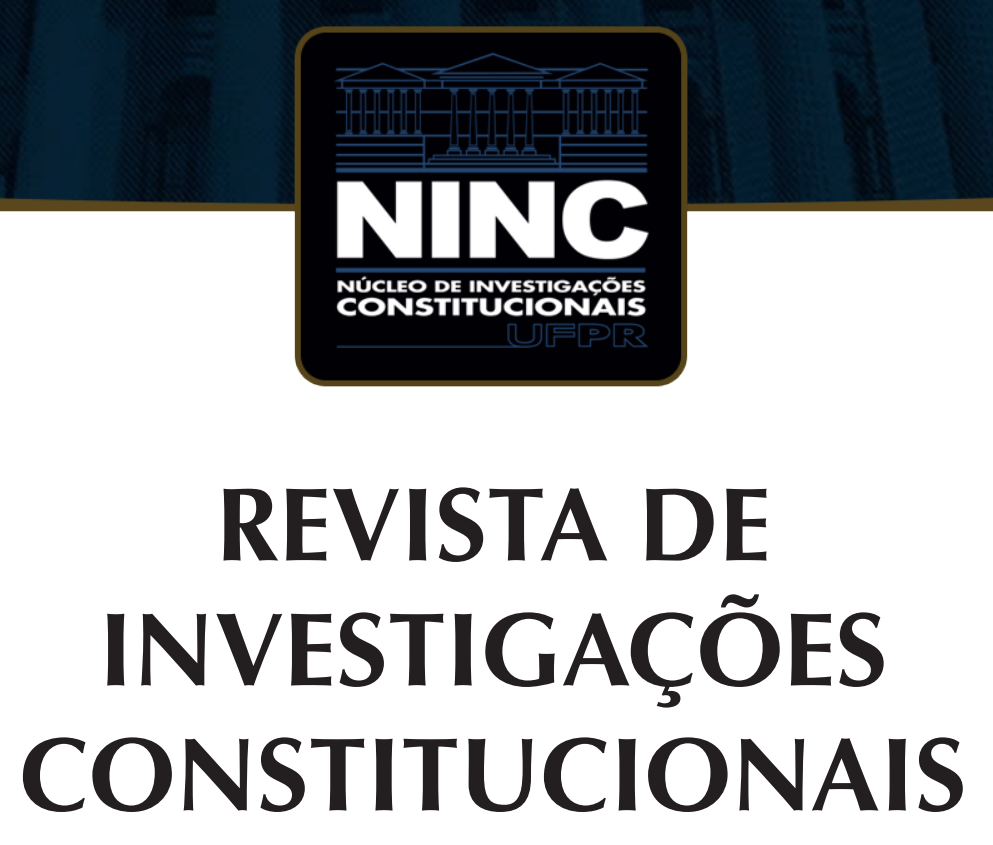

JOURNAL OF CONSTITUTIONAL RESEARCH

vol. 6 | n. 3 | setembro/dezembro 2019 | ISSN 2359-5639 | Periodicidade quadrimestral Curitiba | Núcleo de Investigações Constitucionais da UFPR | www.ninc.com.br 


\title{
As políticas públicas como concretização dos direitos sociais
}

\section{Public policies as realization of social rights}

\author{
OSVALDO FERREIRA DE CARVALHO I,* \\ 'Faculdade Estácio de Sá de Goiás (Goiânia-GO, Brasil) \\ osvaldopesquisador@gmail.com \\ http://orcid.org/0000-0003-0926-7046
}

Recebido/Received: 31.05.2018 / May 31 1 , 2018 Aprovado/Approved: 16.12.2019/ December $16^{\text {th }}, 2019$

\section{Resumo}

Este artigo busca examinar as políticas públicas como concretização dos direitos sociais no âmbito do hodierno Estado Social, corporificado por um extenso catálogo de direitos sociais e, a partir da consagração jurídico-constitucional de tais direitos, eles constituem fundamento das políticas públicas de desenvolvimento ao interessar, aqui, a visão que enquadra os direitos sociais como marco de ação das políticas públicas. Assim, é por meio das políticas públicas que o Estado concretiza os direitos fundamentais, sobretudo os direitos sociais. Ademais, as políticas públicas, nos Estados Constitucionais, se coadunam com o ativismo judicial, já que o Poder Judiciário ao exercer o controle das políticas públicas não substitui as funções dos Poderes Legislativo e Executivo, mas implica, por sua vez, não deixar que a pessoa humana fique desprovida do exercício de um direito fundamental, reconhecido na Constituição ou na lei, porque o Poder Público foi inerte ou omisso. O artigo analisará, ainda, sobre a discricionariedade administrativa na tomada de decisão do agente público no contexto das políticas públicas de direitos sociais. A pesquisa bibliográfica foi, assim, direcionada para a consulta mais pormenorizada de amplo

\section{Abstract}

This article seeks to examine public policies as the realization of social rights within the current Social State, embodied by an extensive catalog of social rights and, from the juridical and constitutional consecration of these rights, they constitute the foundation of public development policies to the to interest, here, the vision that frames social rights as a framework for action of public policies. Thus, it is through public policies that the State concretizes fundamental rights, especially social rights. In addition, public policies in constitutional states are in line with judicial activism, since the judiciary in exercising control of public policies does not replace the functions of the legislative and executive branches, but implies, in turn, human being is deprived of the exercise of a fundamental right, recognized in the Constitution or in the law, because the Public Power was inert or omission. The article will also analyze the administrative discretion in the decision making of the public agent in the context of the public policies of social rights. The bibliographical research was thus directed to the more detailed consultation of ample material available by concentrating all the synergies for the systematization of theoretical and juridical elements with the purpose of erecting

Como citar esse artigo/How to cite this article: CARVALHO, Osvaldo Ferreira de. As políticas públicas como concretização dos direitos sociais. Revista de Investigações Constitucionais, Curitiba, vol. 6, n. 3, p. 773-794, set./dez. 2019. DOI: 10.5380/rinc v6i3.59730.

"Professor da Faculdade Estácio de Sá de Goiás (Goiânia-GO). Pós-doutorando e Doutor em Direito pela Universidade de Lisboa (Lisboa, Portugal). Mestre em Direito pela Pontifícia Universidade Católica de Goiás (PUC-Goiás). Especialista em Direito Público pela Universidade de Brasília (UnB). Especialista em Docência do Ensino Superior. Especialista em Direito Civil e Processual Civil pela Universidade Cândido Mendes (UCAM/RJ). Possui graduação em Ciências Econômicas pela Universidade de Brasília (UnB) e graduação em Direito pela Pontifícia Universidade Católica de Goiás (PUC-Goiás). Professor universitário. Pesquisador. E-mail: osvaldopesquisador@gmail.com.. 
material disponível ao concentrar todas as sinergias para a sistematização de elementos teóricos e jurídicos com o fim erigir argumentos ou soluções que enquadrem os direitos sociais como objeto usual das políticas públicas estatais.

Palavras-chave: Estado Social; Políticas públicas; Direitos sociais; Discricionariedade; Controle judicial.. arguments or solutions that frame social rights as usual object of the state public policies.

Keywords: Social State; Public policy; Social rights; Discretionary; Judicial control.

\section{SUMÁRIO}

1. Introdução; 2. Do estado Social ao papel essencial das políticas públicas como resposta a problemas sociais; 3. Os direitos sociais como marco das políticas públicas de desenvolvimento; 4 . Diversos âmbitos e alcances da intervenção jurisdicional sobre as políticas públicas de direitos sociais; $\mathbf{5}$. Discricionariedade administrativa na formulação de políticas públicas de direitos sociais; $\mathbf{6}$. Conclusão; $\mathbf{7}$. Referências.

\section{INTRODUÇÃO}

As políticas públicas (public policies), embora tenham já sido muito estudadas no âmbito da Ciência Política, da Sociologia, Economia Política, da ciência da Administração e até da Filosofia moral, têm sido correntemente esquecidas do ponto de vista jurídico pela doutrina brasileira.

Os novos problemas que as políticas públicas apresentam continuam a residir na natureza dirigente da Constituição por orientar a ação governamental do estado ao propor que se adote um programa de conformação da sociedade, no sentido de estabelecer uma direção política permanente. Ademais, os atuais problemas atinentes à temática políticas públicas abarcam, ainda, a discricionariedade legislativa, a liberdade de conformação do legislador, bem como a discricionariedade administrativa. A ação político-estatal explica-se pela definição do interesse público primário e da consecução do interesse público secundário, ambos tipicamente compreendidos na atividade estatal, legislativa e administrativa.

A relação entre os direitos sociais e as políticas públicas que procedem à sua realização prática é de extrema importância, pois reside nas políticas públicas a efetiva valorização estatal dos designados direitos sociais não poucas vezes depreciados. Ao levar em conta essa perspectiva, os direitos fundamentais definem-se e aplicam-se como uma espécie de marco ou programa que guia ou orienta as políticas públicas dos Estados ao contribuir para as instituições democráticas.

Expostas as ideias preambulares acima, o objetivo deste artigo busca identificar o papel fundamental das políticas públicas no âmbito do Estado Social de Direito para, em seguida, a partir da concepção de direitos sociais como autênticos direitos fundamentais, identificar qual a vinculação do Estado referente à consecução de políticas 
públicas de direitos sociais e, ao final, apontar que ligada à eficácia jurídica dos direitos sociais poderá configurar a suposta possibilidade de controle jurisdicional das políticas públicas.

Este estudo move-se, dentro do Direito Constitucional, entre a matéria dos direitos fundamentais, sobretudo dos direitos sociais. A análise das políticas públicas, claramente heterogênea, para além do Direito Constitucional, também chama à colação o Direito Administrativo ${ }^{1}$ de quem é parente próximo e, ainda, outras ciências sociais não normativas como, por exemplo, a Ciência Política. ${ }^{2}$

A complexidade do tema proposto perpassa em grande medida da sua heterogeneidade temática ao impedir optar, pura e simplesmente, por um método específico. Poderíamos dizer que nos aproximamos, de certa forma, de uma perspectiva estruturalista, como panorama operante não só mediante análise dos dados textuais constitucionais, legais, doutrinais referentes ao problema a resolver, mas tendo também atenção aos processos de decisão regulados pelas normas atinentes ao problema e à realidade social que para ele remete. Também não exclui o chamado realismo jurídico ao postular a possibilidade de tirar dos princípios imutáveis de justiça as regras de conduta jurídica.

Impende esclarecer que foram privilegiadas, quanto às fontes consultadas, no quadro do objeto de estudo escolhido e delimitado, as obras consideradas como mais importantes, atentando-se com o maior desvelo possível para a atualidade das obras ante as limitações próprias da natureza desta investigação específica. A pesquisa bibliográfica foi, assim, direcionada para a consulta mais pormenorizada de amplo material nos idiomas espanhol, inglês e português (abarcando obras brasileiras e portuguesas). Concentraram-se todas as sinergias numa exaustiva sistematização dos elementos teóricos, jurídicos e metodológicos a fim de erigir um pujante texto límpido, concatenado com vários argumentos e, na ciência de sua incompletude e limitação, submetê-lo ao debate e à crítica.

\footnotetext{
A expressão políticas públicas ingressou recentemente na linguagem e no temário do Direito Administrativo, originada de estudos das ciências sociais realizados nos Estados Unidos. MEDAUAR, Odete. Controle da administração pública. 3. ed. rev. atual. e ampl. São Paulo: RT, 2014. p. 190.

2 Veja-se, a propósito, o garboso texto de Maria Tereza Sadek ao examinar o tema políticas públicas sob a perspectiva da Ciência Política. SADEK, Maria Tereza. Judiciário e arena pública: um olhar a partir da Ciência Política. In: GRINOVER, Ada Pellegrini; WATANABE, Kazuo (Coord.). 0 controle jurisdicional de políticas públicas. 2. ed. Rio de Janeiro: Forense, 2013. p. 1-32.
} 


\section{DO ESTADO SOCIAL AO PAPEL ESSENCIAL DAS POLÍTICAS PÚ- BLICAS COMO RESPOSTA A PROBLEMAS SOCIAIS}

O estudo referente às políticas públicas está intrinsecamente relacionado à existência de um Estado Social ${ }^{3}$ desde a Constituição de Weimar de 1919, ${ }^{4}$ de modo que é imprescindível elucidar o conceito de política pública ao torná-lo operacional para o escopo principal deste artigo que consiste em perceber as políticas públicas como concretização dos direitos sociais e, por consequência, se há possibilidade de controle jurisdicional sobre a rubrica de política pública ao visar a efetivar direitos reconhecidos na Constituição, notadamente os direitos sociais, ante a ausência ou insuficiência ou, ainda, a não concretização de política pública na respectiva matéria. ${ }^{5}$

Pode-se, sem pretensão de precisão, afirmar que os objetivos mais importantes do Estado Social passam pela ajuda contra a necessidade e a pobreza, pela garantia de uma renda mínima que venha assegurar a dignidade da pessoa humana, pelo aumento da igualdade para a superação da dependência, pela segurança contra as vicissitudes da vida (risco social) e pela criação e ampliação de prosperidade. Esquematicamente, impende destacar que, em geral, os objetivos do Estado Social passam a almejar: (a) a segurança econômica e social; (b) a redução das diversas desigualdades; e (c) a redução da pobreza. ${ }^{6}$ Aqui se vê facilmente a função própria que os direitos sociais assumem ao ser possível resumir a sua caracterização em quatro aspectos: $\left(1^{\circ}\right)$ a sua orientação em função do princípio da igualdade material; $\left(2^{\circ}\right)$ o seu vínculo com a satisfação de necessidades individuais; $\left(3^{\circ}\right)$ a intensificação do elemento público que atribui ao Estado

\footnotetext{
3 O Estado Social caracteriza-se pelo adensamento (consolidação) da compreensão da pessoa humana e inerente dignidade, pelo aprofundamento da justiça distributiva e pela promoção entre a igualdade de todos os membros da comunidade, por um apelo a um alargado sentimento de solidariedade. E, nesse pressuposto, ficam os poderes públicos obrigados a intervir para que a igualdade jurídico-política a qual assegura o Estado de Direito se transforme numa autêntica igualdade social, econômica e cultural, o que culmina numa atitude corretiva das desigualdades. O Estado Social (de Direito) assume a atribuição de conformação da ordem social com o intuito de alcançar a justiça social porque a garantia das condições materiais do cidadão digno não dispensa a atuação prestacional do Estado na efetiva realização dos direitos sociais. LUÑO, Antonio Enrique Pérez. Derechos humanos, Estado de Derecho y Constitución. 9. ed. Madrid: Tecnos, 2005. p. 105, 233; SAMPAIO, Jorge Silva. $\mathbf{O}$ controle jurisdicional das políticas públicas de direitos sociais. Coimbra: Coimbra Editora, 2014. p. 167; MORAIS, Carlos Blanco de. Curso de Direito Constitucional: teoria da Constituição em tempo de crise do Estado Social. Coimbra: Coimbra Editora, 2014. Tomo II. v. 2. p. 110-139; BONAVIDES, Paulo. Do Estado Liberal ao Estado Social. 11. ed. São Paulo: Malheiros, 2013. p. 182-204; DANTAS, Miguel Calmon. Constitucionalismo dirigente e pós-modernidade. São Paulo: Saraiva, 2009. p. 171-249; GARCÍA-PELAYO, Manuel. As transformações do Estado contemporâneo. Tradução de Agassiz Almeida Filho. Rio de Janeiro: Forense, 2009. p. 14-16, 22; CANOTILHO, José Joaquim Gomes. Direito Constitucional e teoria da constituição. 7. ed. Coimbra: Almedina, 2003. p. 245; NOVAIS, Jorge Reis. Os princípios constitucionais estruturantes da república portuguesa. Coimbra: Coimbra Editora, 2004. p. 30-46.

$4 \quad$ LIBERATI, Wilson Donizeti. Políticas públicas no Estado Constitucional. São Paulo: Atlas, 2013. p. 81.

5 Nesse sentido: MEDAUAR, Odete. Controle da administração pública. 3. ed. rev. atual. e ampl. São Paulo: RT, 2014. p. 232.

6 ZAMORA, Miguel Agudo. Estado Social y felicidad: la exigibilidad de los derechos sociales en el constitucionalismo actual. Madrid: Ediciones del Laberinto, 2007. p. 50-52.
} 
a responsabilidade em matéria social; e $\left(4^{\circ}\right)$ a sua virtualidade como elementos que operam diante dos mecanismos do mercado. ${ }^{7}$

Nas palavras de Diogo de Figueiredo Moreira Neto, políticas públicas traduzem "[...] um complexo de processos juspolíticos, destinado à efetivação dos direitos fundamentais". ${ }^{8}$ Em alusão à lição de Maria Paula Dallari Bucci, políticas públicas constituem "[...] programas de ação governamental visando a coordenar os meios à disposição do Estado e as atividades privadas, para a realização de objetivos socialmente relevantes e politicamente determinados". ${ }^{9}$ Ainda, segundo a autora, políticas públicas "são metas coletivas conscientes e, como tais, um problema de direito público, em sentido lato". ${ }^{10}$ Assim, por exemplo, erradicar o analfabetismo no Brasil seria uma política pública ao envolver um plano de múltiplas atividades, vários atores ${ }^{11}$ públicos e privados, alocação de recursos, aferição contínua de resultados. ${ }^{12}$

O reconhecimento jurídico-constitucional de direitos fundamentais, ainda que não seja absoluto, ${ }^{13}$ impõe subjetivamente ao Estado obrigações ${ }^{14}$ negativas, tais como a proibição de restrições de direitos desarrazoáveis ou discriminatórias. ${ }^{15}$ Por outro lado, os direitos sociais impõem também ações positivas como, por exemplo, criar

7 SAMPAIO, Jorge Silva. O controle jurisdicional das políticas públicas de direitos sociais. Coimbra: Coimbra Editora, 2014. p. 169.

8 MOREIRA NETO, Diogo de Figueiredo. Quatro paradigmas do Direito Administrativo pós-moderno: legitimidade, finalidade, eficiência, resultados. Belo Horizonte: Fórum, 2008. p. 124.

9 BUCCl, Maria Paula Dallari. Direito administrativo e políticas públicas. São Paulo: Saraiva, 2002. p. 241.

10 BUCCI, Maria Paula Dallari. Direito administrativo e políticas públicas. São Paulo: Saraiva, 2002. p. 241.

11 Para Jorge Silva Sampaio, qualquer indivíduo, pessoa jurídica ou grupo social envolvido no problema coletivo que origina a política pública é ator potencial que poderá entrar no espaço da política em causa. SAMPAIO, Jorge Silva. $\mathbf{O}$ controle jurisdicional das políticas públicas de direitos sociais. Coimbra: Coimbra Editora, 2014. p. 74.

12 MEDAUAR, Odete. Controle da administração pública. 3. ed. rev. atual. e ampl. São Paulo: RT, 2014. p. 192.

13 Há quem não reconhece a existência de direitos fundamentais sociais como, por exemplo, Fernando Atria, o qual admite apenas o significado político de direitos ao constituir o único sentido político de direitos fundamentais sociais, rechaçando o seu sentido jurídico por não serem tais direitos juridicamente exigíveis, de modo que a linguagem do direito é a linguagem da política. ATRIA, Fernando. Existem direitos sociais? In: MELLO, Cláudio Ari (Coord.). Os desafios dos direitos sociais. Porto Alegre: Livraria do Advogado, 2005. p. 9-46, nomeadamente as páginas 24-25, 35-37. Para uma crítica às objeções expostas por Fernando Atria, veja as análises realizadas por Carlos Bernal Pulido no seguinte artigo de sua autoria: PULIDO, Carlos Bernal. Fundamento, conceito e estrutura dos direitos sociais: uma crítica a "Existem direitos sociais?" de Fernando Atria. In: SOUZA NETO, Cláudio Pereira de; SARMENTO, Daniel (Coord.). Direitos sociais: fundamentos, judicialização e direitos sociais em espécie. Rio de Janeiro: Lumen Juris, 2008. p. 137-175.

14 Tradicionalmente são consideradas obrigações do Estado em matéria de direitos sociais (inclusive, em termos mais gerais, em relação a todos os direitos fundamentais) ao compreender três níveis: respeitar, proteger e cumprir ou realizar. Nesse sentido: CARBONELL, Miguel. Los derechos sociales: elementos para una lectura en clave normativa. In: MONTEROS, Javier Espinoza de los; ORDÓÑEZ, Jorge. Los derechos sociales en el Estado Constitucional. Valencia, ES: Tirant lo Blanch, 2013. p. 220; CASTILHO, Ricardo. Justiça social e distributiva: desafios para concretizar direitos sociais. São Paulo: Saraiva, 2009. p. 49-50.

15 Em relação às restrições a direitos fundamentais, conferir: NOVAIS, Jorge Reis. As restrições aos direitos fundamentais não expressamente autorizadas pela Constituição. 2. ed. Coimbra: Coimbra Editora, 2010. p. 155-192. 
instituições dirigidas à ajuda de grupos sociais que se encontrem em situações de desigualdade estrutural, atribuir prestações básicas para suprir necessidades de subsistência, de educação, saúde, moradia e, além disso, impõem o dever positivo de legislar a fim de impedir situações extremas de abuso de partes mais poderosas nas relações contratuais entre particulares, bem como é exigido do Poder Público a observância de regras básicas de procedimento, relacionadas ao modo de organizar serviços e à gestão administrativa dos programas. Logo, a margem de discricionariedade legislativa e administrativa está limitada quando o Estado pretende desenhar (formular) e implementar políticas públicas de concretização do conteúdo de um direito social. ${ }^{16}$

De certa forma, a satisfação de alguns direitos fundamentais sociais como o direito a uma moradia condigna, à educação, à saúde, ao transporte constitui uma "[...] condição material básica para levar uma vida digna, para desenvolver livremente a personalidade e para participar nos assuntos públicos". ${ }^{17}$

É daqui que provém a necessidade de intervenção estatal na vida econômica e social ao estabelecer uma estreita relação entre os direitos sociais e o Estado Social, porquanto "[...] é o Estado que tem capacidade e legitimação para tomar as medidas políticas, econômicas e jurídicas necessárias para favorecer a realização e desenvolvimento dos direitos sociais". ${ }^{18} \mathrm{O}$ Estado Social aparece, assim, perante o Estado de Direito ao estabelecer este suas bases essencialmente na autonomia privada, "[...] adotando como princípio fundamental a realização da justiça social, entendida como correção dos efeitos negativos externos da atividade econômica na situação dos indivíduos".19

Não se discute que a obrigação do indivíduo de se "autogovernar" se situa em primeiro plano, também não se hesita afirmar que, subsidiariamente e caso o indivíduo não seja capaz de obter sozinho os meios que lhe permitam a sua subsistência, é necessária (e, dentro do possível, obrigatória) a ajuda estatal.

Os direitos sociais têm como objetivo último proporcionar os meios necessários aos desfavorecidos para que estes possam, verdadeiramente, participar e desenvolver as suas faculdades na sociedade, o que justifica o Estado Social. ${ }^{20}$ Infelizmente, a privação da riqueza é um dos maiores obstáculos a que as pessoas possam satisfazer por si

\footnotetext{
16 ABRAMOVICH, Victor. El rol de la justicia en la articulación de políticas y derechos sociales. In: ABRAMOVI$\mathrm{CH}$, Victor; PAUTASSI, Laura (Org.). La revisión de las políticas sociales: estudio de casos. Buenos Aires: Editores del Puerto, 2009. p. 1.

17 SARDÀ, Clara Marquet. Los derechos sociales en el ordenamiento jurídico sueco: estudio de una categoría normativa. Barcelona: Atelier, 2010. p. 70.

18 GIMÉNEZ, Teresa Vicente. La exigibilidad de los derechos sociales. València: Tirant lo Blanch, 2006. p. 67

19 SARDÀ, Clara Marquet. Los derechos sociales en el ordenamiento jurídico sueco: estudio de una categoría normativa. Barcelona: Atelier, 2010. p. 70.

20 Acerca do fundamento e a justificação dos direitos sociais no modelo do Estado Social, conferir: CARBONELL, Miguel. Los derechos sociales: elementos para una lectura en clave normativa. In: MONTEROS, Javier Espinoza de los; ORDÓÑEZ, Jorge. Los derechos sociales en el Estado Constitucional. Valencia, ES: Tirant lo Blanch, 2013. p. 201-203.
} 
próprias as suas necessidades e usufruir dos seus direitos ao implicar, pois, a imprescindível (re)distribuição da riqueza que, em última análise, só poderá ser efetuada pelo Estado. ${ }^{21}$

É esta a razão que, perante políticas estatais de redistribuição da riqueza ao encalçar a justiça social e a igualdade material inerentes ao bem-estar - que em sede de Estado Social são verdadeiros "fins essenciais do Estado"22 -, a igualdade deixa de ser o ponto de partida do Direito para converter-se em meta ou aspiração da ordem jurídica. ${ }^{23}$ Desse modo, o Estado Social se sustenta na justiça distributiva ao distribuir bens de conteúdo material, sendo designado pelos alemães como Estado que se responsabiliza pela procura existencial, isto é, o indivíduo desenvolve sua existência dentro de um âmbito constituído por um leque de situações, de bens e serviços materiais e imateriais, cujas possibilidades de existência o indivíduo não pode assegurar por si mesmo. ${ }^{24}$

Em síntese, o Estado assume um dever duplo no âmbito de todos os direitos fundamentais ao se traduzir na realização de políticas públicas de direitos sociais que serão materializadas tanto por atuações normativas como a aprovação de leis, como por atuações fáticas, ligadas normalmente à execução dessas leis. Por um lado, o Estado encontra-se jurídico-constitucionalmente comprometido com um dever de proteção dos direitos fundamentais e, por outro lado, com um dever de promoção desses mesmos direitos. ${ }^{25}$ É a consecução estatal destes dois deveres que corporiza normativamente as políticas públicas de direitos sociais.

A Constituição delimita, desta forma, ela própria o modo de concretização do Estado Social mediante definição de tarefas ou incumbências ao impor constitucionalmente deveres ao Estado e, deixando neste campo, a atividade pública finalística ou teleologicamente orientada para a realização de um fim: os direitos sociais. ${ }^{26}$ Cabe ao texto constitucional proceder à articulação entre um conjunto de princípios políticos para os quais as instituições estatais devem efetivar, entre os quais se encontram quase sempre direitos fundamentais e os respectivos deveres estatais. E, nesse sentido, os direitos fundamentais (como os sociais), qual agenda pública conformadora, servem para canalizar ou orientar as instituições públicas. ${ }^{27}$

21 GIMÉNEZ, Teresa Vicente. La exigibilidad de los derechos sociales. València: Tirant lo Blanch, 2006. p. 67.

22 NOVAIS, Jorge Reis. Os princípios constitucionais estruturantes da república portuguesa. Coimbra: Coimbra Editora, 2004. p. 31.

23 RADBRUCH, Gustav. Introducción a la filosofía del derecho. Tradução de Wenceslao Roces. Ciudad de México: Fondo de Cultura Económica, 1955. p. 162.

24 GARCÍA-PELAYO, Manuel. As transformações do Estado contemporâneo. Tradução de Agassiz Almeida Filho. Rio de Janeiro: Forense, 2009. p. 14-16.

25 NOVAIS, Jorge Reis. Direitos sociais: teoria jurídica dos direitos sociais enquanto direitos fundamentais. Coimbra: Coimbra Editora, 2010. p. 261-262.

26 OTERO, Paulo. Direito constitucional português: identidade constitucional. Coimbra: Almedina, 2010. v. 1. p. 101.

27 KING, Jeff. Judging social rights. Cambridge, UK: Cambridge University Press, 2012. p. 51. 
A ação estatal, com as políticas públicas, deixa de ser programada para meramente cumprir e executar normas. O Estado ganha uma função comunitária flexível, identificável pelos fins que tem realizar e que, para além disso, não podem ser definidos em toda a sua dimensão, porquanto os processos de evolução da vida, pela sua complexidade, não se deixam abranger por prognósticos em si incompletos.

Apesar desta íntima e nítida relação entre direitos fundamentais e políticas públicas, e do expresso mandato constitucional, o mundo das políticas públicas sociais sempre esteve relutante em assumir as derivações do debate constitucional sobre o reconhecimento da exigibilidade dos direitos sociais. Os versados em políticas sociais costumavam reputar que os direitos têm pouco a dizer sobre políticas públicas e que a ambiguidade e indeterminação das normas que os consagram não permitiriam que se fixassem como marcos ou guias orientadoras na formulação das políticas. Para além disso, a visão dos direitos fundamentais, principalmente dos direitos sociais, como orientadores ou critérios de fiscalização poderia "[...] atar as políticas a esquemas rígidos, próprios do mundo jurídico, que não permitiriam responder às variáveis conjunturas e obstavam à consecução eficaz da ação pública".28

Em suma, embora apareçam hoje como aliados óbvios, os direitos sociais e as políticas públicas permaneceram distantes por muito tempo. Com efeito, apenas recentemente as políticas têm constituído um verdadeiro instrumento para a proteção, garantia e promoção dos direitos fundamentais em geral e dos direitos sociais em particular. ${ }^{29}$ O futuro dos direitos sociais e o futuro de milhões de pessoas excluídas e condenadas a viver na pobreza depende de um uso coerente e inteligente de diversas estratégias, tanto políticas como sociais, jurídicas e econômicas para a realização efetiva dos direitos fundamentais em contextos desvantajosos pela ausência do desenho institucional adequado por falta de vontade política e pela carência de um trabalho intelectual constante e imaginativo para resolver os problemas sociais que afligem o fraturado e complexo mundo atual. ${ }^{30}$

\footnotetext{
28 ABRAMOVICH, Víctor. El rol de la justicia en la articulación de politicas y derechos sociales. ABRAMOVICH, Víctor; PAUTASSI, Laura (Org.). La revisión de las políticas sociales: estudio de casos. Buenos Aires: Editores del Puerto, 2009. p. 8. Tradução nossa.

29 MURCIA, Luis Eduardo Pérez; YEPES, Rodrigo Uprimny; GARAVITO, César Rodríguez. Introducción. In: MURCIA, Luis Eduardo Pérez; YEPES, Rodrigo Uprimny; GARAVITO, César Rodríguez (Org.). Los derechos sociales en serio: hacia un diálogo entre derechos y políticas públicas. Bogotá: DeJuSticia, 2007. p. 17.

30 ARANGO, Rodolfo. Los derechos sociales en Iberoamérica: estado de la cuestión y perspectivas de futuro. Cuaderno Electrónico, Madrid, n. 5, p. 17-18, 2009.
} 


\section{OS DIREITOS SOCIAIS COMO MARCO DAS POLÍTICAS PÚBLI- CAS DE DESENVOLVIMENTO}

Em nosso entender os direitos fundamentais ao abranger os direitos sociais, a partir da sua consagração jurídico-constitucional, apresentam-se não apenas como limites, mas também como fundamento das políticas públicas de desenvolvimento ${ }^{31} \mathrm{e}$ interessa-nos a visão que enquadra os direitos sociais como marco de ação das políticas públicas. ${ }^{32}$ Além disso, as políticas públicas constituem a base de um conjunto de atividades a ser realizadas pela Administração Pública, para que os fins consagrados no texto constitucional sejam cumpridos, sobretudo no que se refere aos direitos fundamentais que dependem de ações para sua promoção. ${ }^{33}$

Essa corrente de interpretação das políticas públicas a partir dos direitos fundamentais, em especial dos direitos sociais, foi desenvolvida por organismos internacionais de cooperação para o desenvolvimento e realização dos direitos humanos. ${ }^{34}$ Buscamos, pois, alçar a ideia dos direitos sociais como importantes marcos, fundamentos para as políticas públicas de direitos sociais.

Em primeiro lugar, cumpre consignar que a utilização de direitos como marco das políticas de desenvolvimento não é propriamente um tema consensual no âmbito dos formuladores de políticas públicas e dos organismos multilaterais de cooperação para o desenvolvimento e de direitos humanos..$^{35} \mathrm{O}$ que acontece é que, às vezes, a ado-

31 Há, pois, uma uma inter-relação entre "direitos, políticas e desenvolvimento". GAVARA DE CARA, Juan Carlos. La dimensión objetiva de los derechos sociales. Barcelona: Bosch, 2010. p. 74; MURCIA, Luis Eduardo Pérez. Desarrollo, derechos sociales y políticas públicas. In: MURCIA, Luis Eduardo Pérez; YEPES, Rodrigo Uprimny; GARAVITO, César Rodríguez (Org.). Los derechos sociales en serio: hacia un diálogo entre derechos y políticas públicas. Bogotá: DeJuSticia, 2007. p. 86.

32 De acordo com Luis Eduardo Pérez Murcia, existem outras análises teóricas que, a partir da Economia e do Direito foram sendo formuladas em torno da relação entre direitos, desenvolvimento e políticas públicas, nomeadamente: (a) a incorporação dos direitos como âmbito de valoração do bem-estar; (b) a incorporação dos direitos e das liberdades como fundamento do conceito de desenvolvimento humano; e (c) a proposta de integrar os direitos como marco de ação das políticas de desenvolvimento. MURCIA, Luis Eduardo Pérez. Desarrollo, derechos sociales y políticas públicas. In: MURCIA, Luis Eduardo Pérez; YEPES, Rodrigo Uprimny; GARAVITO, César Rodríguez (Org.). Los derechos sociales en serio: hacia un diálogo entre derechos y políticas públicas. Bogotá: DeJuSticia, 2007. p. 86-121.

33 BARCELLOS, Ana Paula de. Neoconstitucionalismo, direitos fundamentais e controle das políticas públicas. In: CAMARGO, Marcelo Novelino (Org.). Leituras complementares de Direito Constitucional: direitos fundamentais. 2. ed. rev. e ampl. Salvador: Juspodivm, 2007. p. 51.

34 Assim, instâncias como o Alto Comissariado das Nações Unidas para os Direitos Humanos (ACNUDH), o Programa das Nações Unidas para o Desenvolvimento (PNUD) e o Fundo das Nações Unidas para a Infância (UNICEF) impulsionaram o trabalho de extrair o conteúdo dos direitos humanos e das obrigações dos Estados como guia para o desenho e implementação de política de desenvolvimento e luta contra a pobreza. Especificamente o Alto Comissariado das Nações Unidas para os Direitos Humanos assinalou que um enfoque dos direitos humanos referentes à pobreza incluirá um reconhecimento explícito do marco normativo dos direitos humanos nacionais e internacionais.

35 MURCIA, Luis Eduardo Pérez. Desarrollo, derechos sociales y políticas públicas. In: MURCIA, Luis Eduardo Pérez; YEPES, Rodrigo Uprimny; GARAVITO, César Rodríguez (Org.). Los derechos sociales en serio: hacia un diálogo entre derechos y políticas públicas. Bogotá: DeJuSticia, 2007. p. 101. 
ção de direitos fundamentais como parâmetro de formulação, implementação e avaliação de políticas públicas é interpretada por setores do Poder Executivo como uma restrição da margem de discricionariedade que lhes caberia no manejo das políticas e, inclusive, como uma forma de ampliar as obrigações do Estado. ${ }^{36}$

Parece óbvio que as políticas públicas em geral e as sociais em particular, não obstante o limite de conformação política dos poderes públicos, não podem deixar de ter em atenção os deveres estatais de respeito, proteção e promoção dos direitos fundamentais; aliás, na nossa opinião, esses deveres acarretam um papel fundamentação na formulação das políticas públicas. À luz dos direitos fundamentais sociais, não pode uma política pública ser juridicamente legitima se restringir injustificadamente algum direito fundamental ou criar barreiras que possam limitar a sua plena realização. ${ }^{37}$

Como exemplo, imaginemos que a formulação de uma política pública na área de educação com vistas na ampliação da cobertura do sistema de ensino - um objetivo jurídico-constitucionalmente válido ${ }^{38}$-, vem restringir o princípio da gratuidade da educação básica ${ }^{39}{ }^{40}$ ao estabelecer o pagamento de mensalidade para este nível de ensino. Esta política pública ao violar diretamente um parâmetro jurídico-constitucional concreto é obviamente inconstitucional e deve ser sujeita ao escrutínio da justiça constitucional. Ora, é extremamente importante para aqueles que formulam as políticas públicas tenham sempre em atenção os direitos fundamentais como marcos da sua atuação, seja como elemento orientador ou conformador.

Em segundo lugar, é importante valer-se do princípio da interdependência, segundo o qual a adoção dos direitos como marco das políticas sociais implica, de forma especial, que as entidades estatais sob o encargo da formulação e implementação das

36 Consoante elucida Luis Eduardo Pérez Murcia, esta postura evidencia algum desconhecimento por parte da Administração Pública quanto à natureza e alcance das obrigações estatais em matéria de direitos fundamentais. em rigor, as obrigações existem independentemente da formulação de políticas públicas pelo Estado para o seu cumprimento. O objetivo passa por mostrar às entidades estatais responsáveis por desenhar (formular) e pôr em marcha as políticas públicas que o enfoque de direitos não se trata de uma mera fonte de novas obrigações, mas um excelente mecanismo para as cumprir. MURCIA, Luis Eduardo Pérez. Desarrollo, derechos sociales y políticas públicas. In: MURCIA, Luis Eduardo Pérez; YEPES, Rodrigo Uprimny; GARAVITO, César Rodríguez (Org.). Los derechos sociales en serio: hacia un diálogo entre derechos y políticas públicas. Bogotá: DeJuSticia, 2007. p. 101.

37 MURCIA, Luis Eduardo Pérez. Desarrollo, derechos sociales y políticas públicas. In: MURCIA, Luis Eduardo Pérez; YEPES, Rodrigo Uprimny; GARAVITO, César Rodríguez (Org.). Los derechos sociales en serio: hacia un diálogo entre derechos y políticas públicas. Bogotá: DeJuSticia, 2007. p. 102.

38 Conforme dicção do artigo 205 da Constituição Federal de 1988: "A educação, direito de todos e dever do Estado e da família, será promovida e incentivada com a colaboração da sociedade, visando ao pleno desenvolvimento da pessoa, seu preparo para o exercício da cidadania e sua qualificação para o trabalho".

39 A educação básica (terminologia adotada pelo legislador constituinte no art. 208 da CRFB/1988) é denominada de ensino fundamental pelo artigo 32 da Lei n 9.394, de 20 de dezembro de 1996 (Lei de Diretrizes e Bases da Educação Nacional).

40 Em conformidade com o disposto no artigo 208, inciso I da Constituição Federal de 1988, a educação básica é obrigatória e gratuita dos 4 (quatro) aos 17 (dezessete) anos de idade ao ser, inclusive, assegurada a oferta gratuita para todos os que a ela não tiveram acesso na idade própria. 
políticas prefiram medidas que tenham em atenção a inter-relação existente entre os direitos fundamentais. A incorporação dos princípios da integração e da interdependência nas políticas públicas é um primeiro passo para superar as intervenções setoriais que, a partir de um sujeito fragmentado, não garantem que as múltiplas ações estatais convirjam no sentido dos direitos. De outra forma, reconhecer a interdependência dos direitos fundamentais permite que as políticas públicas sejam construídas com o objetivo de satisfazer um ou vários direitos ou, ao contrário, erigir barreiras mais fortes para o controle de políticas que desvalorizem a linguagem dos direitos. ${ }^{41}$

Cumpre consignar que a natureza constitucional dos direitos sociais esparge a sua força contribuindo decisivamente para a forma como as políticas públicas são implementadas ao aparecer estas como o mais importante dos instrumentos de operacionalização dos deveres positivos de direitos fundamentais. De onde se extrai que é por meio das políticas públicas que o Estado concretiza os direitos fundamentais e, assim, protege, garante e promove o acesso individual aos bens jusfundamentais.

O Estado Constitucional, ${ }^{42}$ designação sintética do Estado Democrático e Social de Direito que se reconhece consagrado pela Constituição brasileira de 1988 (sem dúvida, com suas peculiaridades), afigura-se nitidamente comprometido com os direitos fundamentais e com a mudança social, ${ }^{43}$ conforme se observa na simples leitura do artigo $3^{\circ}$ ao traçar os objetivos da República Federativa do Brasil, busca erigir os direitos sociais não como interesses ou aspirações éticas. ${ }^{44}$

Isso posto, o ato de relacionar direitos fundamentais com políticas públicas e, em especial, com políticas públicas de direitos sociais abre a porta à possibilidade de um maior controle ou intervenção judicial na ação governamental, sem violação da separação dos poderes, aumentando a transparência ao suscitar que mais cidadãos e organizações sociais possam recorrer ao Poder Judiciário sempre que o Poder Público não venha implementar políticas públicas constitucionalmente devidas ou realizar outras frontalmente contrárias ao texto constitucional. ${ }^{45}$

\footnotetext{
41 MURCIA, Luis Eduardo Pérez. Desarrollo, derechos sociales y políticas públicas. In: MURCIA, Luis Eduardo Pérez; YEPES, Rodrigo Uprimny; GARAVITO, César Rodríguez (Org.). Los derechos sociales en serio: hacia un diálogo entre derechos y políticas públicas. Bogotá: DeJuSticia, 2007. p. 106.

42 Não se desconhece a multiplicidade de significados atribuídos ao vocábulo. SANCHÍS, Luis Prieto. Justicia constitucional y derechos fundamentales. Madrid: Trotta, 2003. p. 107.

43 SARLET, Ingo Wolfgang. A eficácia dos direitos fundamentais: uma teoria geral dos direitos fundamentais na perspectiva constitucional. 12. ed. rev. atual. e ampl. Porto Alegre: Livraria do Advogado, 2015. p. 60.

44 CANOTILHO, José Joaquim Gomes. Direito Constitucional e teoria da constituição. 7. ed. Coimbra: Almedina, 2003. p. 377.

45 ABRAMOVICH, Victor. El rol de la justicia en la articulación de políticas y derechos sociales. In: ABRAMOVI$\mathrm{CH}$, Victor; PAUTASSI, Laura (Org.). La revisión de las políticas sociales: estudio de casos. Buenos Aires: Editores del Puerto, 2009. p. 8.
} 


\section{DIVERSOS ÂMBITOS E ALCANCES DA INTERVENÇÃO JURISDI- CIONAL SOBRE AS POLÍTICAS PÚBLICAS DE DIREITOS SOCIAIS}

Alguma doutrina procura simplesmente rejeitar a possibilidade de controle jurisdicional das políticas públicas ao apontar, por exemplo, a falta de legitimidade do Poder Judiciário para o controle ao substituir a discricionariedade administrativa e a discricionariedade do legislador pela discricionariedade do juiz, a ausência de idoneidade técnica do Poder Judiciário em matéria de destinação dos recursos orçamentários, a ocorrência de insegurança jurídica na atuação ilegítima do Poder Judiciário nas políticas públicas e a infringência ao princípio da separação dos poderes com a invasão do Poder Judiciário na esfera de atribuições dos outros poderes (Legislativo e Executivo). ${ }^{46}$

Entretanto, cumpre sustentar a possibilidade de o Poder Judiciário fiscalizar a constitucionalidade e a legalidade de políticas públicas de direitos sociais (educação, moradia, saúde, transporte, previdência social etc.) ao exercer um papel de elemento catalisador ao considerar que o controle será mais ou menos intenso em função das características concretas de cada caso. O Poder Judiciário aparece, portanto, como um verdadeiro ator silencioso na conformação de políticas públicas ao acabar por obrigar as diversas entidades como a própria Administração Pública, o legislador, os grupos de interesse e os movimentos sociais que representam os desfavorecidos queixosos, a interagir entre elas. ${ }^{47}$

Assim, o controle jurisdicional de políticas públicas de direitos sociais é possível e admissível ao existir a probabilidade de tal controle "[...] assumir matizes e alcances muito diversos que abrem um espectro enorme para determinar graus de ativismo judicial". ${ }^{48} \mathrm{O}$ aspecto fundamental de qualquer estudo sobre a judicialização de políticas públicas deve observar como incidem certos marcos institucionais que definem sobre que matéria decide, o que ordena e como decide o Poder Judiciário nestes aspectos. ${ }^{49}$

Em alusão ao magistério de Víctor Abramovich, pode-se ordenar os tipos de matérias ou assuntos sobre os quais o Poder Judiciário pode ser chamado a decidir no âmbito das políticas públicas de direitos sociais em cinco grupos de decisões jurisdicionais: (a) as que invalidam políticas públicas por contrariarem parâmetros jurídicos; (b) as que impõem a implementação de políticas definidas pelas instâncias políticas e não

\footnotetext{
46 DI PIETRO, Maria Sylvia Zanella. Direito Administrativo. 31. ed. rev. atual. e ampl. Rio de Janeiro: Forense, 2018. p. 936-941.

47 SAMPAIO, Jorge Silva. O controle jurisdicional das políticas públicas de direitos sociais. Coimbra: Coimbra Editora, 2014. p. 475.

48 ABRAMOVICH, Victor. El rol de la justicia en la articulación de políticas y derechos sociales. In: ABRAMOVI$\mathrm{CH}$, Victor; PAUTASSI, Laura (Org.). La revisión de las políticas sociales: estudio de casos. Buenos Aires: Editores del Puerto, 2009. p. 50.

49 ABRAMOVICH, Victor. El rol de la justicia en la articulación de políticas y derechos sociales. In: ABRAMOVI$\mathrm{CH}$, Victor; PAUTASSI, Laura (Org.). La revisión de las políticas sociales: estudio de casos. Buenos Aires: Editores del Puerto, 2009. p. 50.
} 
são executadas pela Administração; (c) as que obrigam a formular e executar políticas públicas como, por exemplo, a obrigação de empreender reformas estruturais de determinados sistemas de proteção e promoção de direitos sociais, a partir da aplicação direta das normas constitucionais; (d) as que reconfiguram aspectos parciais das políticas públicas de direitos sociais em curso como, por exemplo, obrigar a ampliar o alcance das prestações e serviços a pressupostos não contemplados e beneficiários excluídos; e (e) aquelas que impõem a reformulação dos procedimentos para a elaboração e implementação das políticas, os espaços de participação ou os níveis de informação pública disponível sobre elas. ${ }^{50}$

Conforme foi expendido, um modelo de Constituição com direitos fundamentais sociais e um amplo sistema de garantias amplia o poder dos juízes perante o Poder Legislativo e Executivo, mas ao mesmo tempo, demanda, como forma de assegurar o funcionamento do sistema político, que os juízes sejam imparciais, que tenham capacidade de resistir a pressões e que, ademais, tomem a Constituição a sério ao ponderar, efetivamente, os diversos bens jurídico-constitucionais que a mesma consagra.

\section{DISCRICIONARIEDADE ADMINISTRATIVA NA FORMULAÇÃO DE POLÍTICAS PÚBLICAS DE DIREITOS SOCIAIS}

O campo das políticas públicas é, historicamente, o ambiente da discricionariedade administrativa. ${ }^{51}$ Tal fato encontra justificativa em duas razões: a primeira, porque esse caráter provedor do Estado se mostra mais intensa na efetivação de políticas sociais; a segunda, porque as normas fundamentadoras dessas políticas encontram abrigo na Constituição brasileira de 1988 e são marcadas pelo caráter diretivo ${ }^{52}$ da realização dos direitos fundamentais, nomeadamente os direitos sociais. Assim, ao mesmo tempo em que as políticas públicas possuem fundamento em normas constitucionais de valor semântico consideravelmente aberto ao atribuir maior discricionariedade ${ }^{53}$ ao

50 ABRAMOVICH, Victor. El rol de la justicia en la articulación de políticas y derechos sociales. In: ABRAMOVI$\mathrm{CH}$, Victor; PAUTASSI, Laura (Org.). La revisión de las políticas sociales: estudio de casos. Buenos Aires: Editores del Puerto, 2009. p. 50.

51 DANIEL, Juliana Maia. Discricionariedade administrativa em matéria de políticas públicas. In: GRINOVER, Ada Pellegrini; WATANABE, Kazuo (Coord.). $O$ controle jurisdicional de políticas públicas. 2. ed. Rio de Janeiro: Forense, 2013. p. 113.

52 As normas diretivas (ou programáticas) existentes num texto constitucional são indissociáveis do Estado Social e por isso, falar em norma diretiva ou programática implica, necessariamente, falar de normas de direito social. FERRARY, Regina Maria Macedo Nery. Normas constitucionais programáticas: normatividade, operatividade e efetividade. São Paulo: RT, 2001. 157, 188.

53 Em alusão ao profícuo magistério de Celso Antônio Bandeira de Mello, por discricionariedade pode ser entendida como "[...] a margem de liberdade que remanesça ao administrador para eleger, segundo critérios consistentes de razoabilidade, um dentre pelo menos dois comportamentos cabíveis, perante cada caso concreto, a fim de suprir o dever de adotar a solução mais adequada a satisfação da finalidade legal, quando, por força da fluidez das expressões da lei ou da liberdade conferida no mandamento, dela não se possa extrair 
administrador, exigem deste uma atuação direta para consecução dos direitos sociais que visa a tutelar.

A natureza diretiva das normas constitucionais, - porquanto veiculam princípios e diretrizes a serem seguidos na elaboração de um programa a ser desenvolvido ,$-^{54}$ cujas finalidades vêm estatuídas na forma de conceitos de valor, são irredutíveis a uma objetividade completa. Nessas situações, além de toda a interpretação possível, remanescerá sempre ao administrador alguma discricionariedade em sua escolha diante do caso concreto. Se por um lado o peso semântico aberto dos princípios e dos direitos fundamentais é indispensável para alcançar o comportamento ótimo exigido do administrador na aplicação da norma; por outro lado, a margem de liberdade acaba por propiciar arbitrariedades pelo agente estatal caso este realize uma escolha que não se coadune com os princípios estabelecidos na Constituição, de modo que sua conduta não estará, pois, pautada, pela discricionariedade e, sim, pela arbitrariedade. Assim, sempre que a conduta da Administração ultrapassar os limites da discricionariedade limites estes que vão além da finalidade legal ao englobar os princípios fundamentais e o dever da boa administração - o Poder Judiciário, uma vez provocado, estará autorizado a intervir. ${ }^{55}$

Cumpre mencionar que a possibilidade de controle judicial não significa, $a$ priori, judicialização invasiva ou a falta de deferência à esfera administrativa. $\mathrm{O}$ mérito administrativo (assim entendido como os aspectos de oportunidade e conveniência diante do interesse público a atingir) poderá ser suscetível de controle judicial, contudo essa afirmação precisa ser aceita em seus devidos termos, pois o que o Poder Judiciário pode fazer é verificar se, ao decidir discricionariamente, a Administração Pública não exorbitou (ultrapassou) os limites da discricionariedade. Em outras palavras, o juiz realiza o controle para averiguar se realmente tratava de mérito, porquanto ao interpretar primeiramente a norma (com a aplicação, por exemplo, dos princípios da proporcionalidade, razoabilidade, moralidade) diante do caso concreto a ele submetido, poderá concluir se a norma outorgou ou não diferentes opções à Administração Pública válidas perante a ordem jurídica e, por conseguinte, deliberar pela não interferência na discricionariedade administrativa (o mérito existe nos atos discricionários). ${ }^{56}$ É evidente que

objetivamente, uma solução unívoca para a situação vertente". MELLO, Celso Antônio Bandeira de. Discricionariedade e controle jurisdicional. 2. ed. São Paulo: Malheiros, 2010. p. 48.

54 MEIRELES, Ana Cristina Costa. A eficácia dos direitos sociais. Salvador: Juspodivm, 2008. p. 246.

55 A interferência do Poder Judiciário ocorrerá basicamente de duas formas: (a) caso se trate de conduta comissiva da Administração Pública que venha contrariar a norma constitucional, o ato será declarado inconstitucional e, portanto, nulo; (b) se a conduta for omissiva, isto é, caso a Administração deixe de agir quando deveria fazê-lo por determinação constitucional, - se configurar ato arbitrário -, o Poder judiciário determinará a consecução daquele ato considerado omisso.

56 DI PIETRO, Maria Sylvia Zanella. Direito Administrativo. 31. ed. rev. atual. e ampl. Rio de Janeiro, 2018. p. 249, 250-251. 
tanto os atos arbitrários do ente público quanto a omissão antijurídica serão sempre suscetíveis de serem controlados e corrigidos pelo Poder Judiciário. ${ }^{57}$

Consoante lição de Maria Sylvia Zanella Di Pietro, com o passar dos tempos, inúmeras teorias foram sendo elaboradas para justificar a extensão do controle judicial sobre aspectos antes considerados como abrangidos pelo conceito de mérito. A teoria do desvio de poder permitiu o exame da finalidade do ato, inclusive sob o aspecto do atendimento do interesse público; a teoria dos motivos determinantes permitiu o exame dos fatos ou motivos que levaram à prática do ato; a teoria dos conceitos jurídicos indeterminados e a sua aceitação como conceitos jurídicos permitiu que o Judiciário passasse a examiná-los e a entrar em aspectos que também eram considerados de mérito; a chamada constitucionalização dos princípios da Administração também veio limitar a discricionariedade administrativa e possibilitar a ampliação do controle judicial sobre os atos discricionários. ${ }^{58}$

As políticas públicas ao serem suscetíveis de uma multiplicidade de arbitrariedades praticadas por agentes públicos no exercício da sua função, não pode ser outro o ponto de vista de que o Poder Judiciário tem o dever de coibir os abusos neste contexto, com o fim de que seja alcançada a realização dos direitos sociais.

Todavia, ao versar sobre política pública implica necessariamente discorrer o fato de que as ações estatais capazes de realizar os direitos fundamentais (incluídos aqui os direitos sociais) pressupõem decisões acerca do dispêndio de recursos públicos. ${ }^{59}$

As políticas públicas são, pois, indispensáveis para a garantia e a promoção de direitos fundamentais, contudo toda e qualquer ação estatal envolve gasto de dinheiro público e os recursos públicos são limitados. Essas são evidências fáticas e não teses jurídicas. A rigor, a simples existência dos poderes estatais - o Executivo, o Legislativo e o Judiciário - implica dispêndio permanente de recursos públicos, ao menos com a manutenção das instalações físicas e remuneração dos titulares e dos servidores públicos, além de outros custos. ${ }^{60}$

Posto isso, deverá ser objeto de controle judicial a adequação da política pública às diretrizes orçamentárias e aos princípios magnos de estatura constitucional; além disso, há intervenção do Poder Judiciário sobre a destinação das verbas vinculadas à

57 FREITAS, Juarez. O controle dos atos administrativos e os princípios fundamentais. 4. ed. São Paulo: Malheiros, 2009. p. 48.

58 DI PIETRO, Maria Sylvia Zanella. Direito Administrativo. 31. ed. rev. atual. e ampl. Rio de Janeiro, 2018. p. 249-250.

59 BARCELLOS, Ana Paula de. Constitucionalização das políticas públicas em matéria de direitos fundamentais: o controle político-social e o controle jurídico no espaço democrático. In: SARLET, Ingo Wolfgang; TIMM, Luciano Benetti (Org.). Direitos fundamentais: orçamento e "reserva do possível. Porto Alegre: Livraria do Advogado, 2008. p. 116.

60 GALDINO, Flávio. O custo dos direitos. In: TORRES, Ricardo Lobo (Org.). Legitimação dos direitos humanos. Rio de Janeiro: Renovar, 2002. p. 139-222. 
saúde e à educação, bem como o exame das prioridades. Isso porque, por um lado, muito embora não se discuta que é o administrador público quem melhor conhece a realidade administrativa e financeira do ente público; por outro lado, é necessário evitar que, na prática, a discricionariedade não se transforme em indulgência ao propiciar que o agente estatal venha desenvolver políticas públicas a seu talante (arbítrio).

Logo, à medida que a discricionariedade do agente venha buscar a escolha das prioridades orçamentárias, essa não pode ser imune ao controle judicial sob o manto de juízos de "oportunidade e conveniência" ínsitos ao comportamento da Administração Pública. Afinal, é a peça orçamentária que permite a existência e o manejo dos recursos necessários à efetivação máxima das políticas públicas. Daí por que toda e qualquer discussão de omissão ou inércia administrativa na implementação de políticas públicas recai sobre o orçamento, sobretudo à luz da cláusula da "reserva do possível", ${ }^{61}$ tão invocado pela Administração Pública para afastar o controle do Poder Judiciário da conduta administrativa omissiva ou inerte. É preciso, pois, repelir as atitudes irresponsáveis, as omissões arbitrárias que venha ameaçar a própria efetividade das determinações do sistema constitucional.

A viabilização do controle jurisdicional de políticas públicas de direitos sociais e dogmaticamente legítimo depende da definição de parâmetros de controle aplicáveis que, consoante elucida Ana Paula de Barcellos, deve compreender: (a) fixação de metas e prioridades; (b) quantidade de recursos a serem investidos; (c) obtenção das metas inicialmente fixadas; e (d) eficiência mínima na aplicação dos recursos. ${ }^{62}$

Os poderes públicos encontram-se vinculados jurídico-constitucionalmente a perseguir atuações positivas que visem a proteger, garantir e promover todos os direitos fundamentais. É a força da Constituição na sua vertente objetiva que a isso obriga e é preciso, pois, levar o texto constitucional a sério. ${ }^{63}$

A otimização dos direitos sociais deveria, pois, numa situação perfeita, ser total, ao ficar os poderes públicos obrigados a prover tudo aquilo que fosse necessário para que todos tivessem as mesmas oportunidades para o acesso individual aos bens jusfundamentais, o que quer que isso significasse. No entanto, a realidade está muito longe

\footnotetext{
61 Sustentamos que a cláusula (ou teoria) da reserva do possível, por se alinhar à ideologia do Estado Liberal, é incompatível com as características intervencionistas e programáticas do Estado Social. Assim sendo, trata-se de argumento insubsistente que não pode ser invocado para paralisar a conduta proativa do Poder Judiciário e das demais formas de expressão do poder estatal. Nesse sentido: CANELA JÚNIOR, Osvaldo. O orçamento e a "reserva do possível": dimensionamento no controle judicial de políticas públicas. In: GRINOVER, Ada Pellegrini; WATANABE, Kazuo (Coord.). O controle jurisdicional de políticas públicas. 2. ed. Rio de Janeiro: Forense, 2013. p. 234;

62 BARCELLOS, Ana Paula de. Neoconstitucionalismo, direitos fundamentais e controle das políticas públicas. In: CAMARGO, Marcelo Novelino (Org.). Leituras complementares de Direito Constitucional: direitos fundamentais. 2. ed. rev. e ampl. Salvador: Juspodivm, 2007. p. 43-64.

63 ABRAMOVICH, Victor; COURTIS, Christian. Los derechos sociales como derechos exigibles. 2. ed. Madrid: Editorial Trotta, 2004. p. 21.
} 
desta situação utópica, haja vista que nos encontramos numa situação de escassez moderada; mas mesmo inexistindo recursos suficientes para tudo fornecer, normalmente os Estados possuem recursos suficientes para melhor ou pior, alguma coisa prover. $^{64}$

Não se pode negar, pois, que para a implementação das políticas públicas de direitos sociais há um custo que "[...] assume especial relevância no âmbito de sua eficácia e efetivação, significando, pelo menos, para grande parte da doutrina, que a efetiva realização das prestações reclamadas não é possível, sem que se aloque algum recurso, dependendo, em última análise, da conjuntura econômica" ${ }^{65}$

A alegação feita pela administração pública da falta de recursos financeiros a fim de concretizar os serviços necessários induz à conduta absenteísta e limitadora do Estado que, por sua vez, reforça a teoria da reserva do possível, ${ }^{66}$ isto é, o Estado somente executará políticas públicas de direitos sociais se tiver recursos suficientes para sua realização. ${ }^{67}$ A reserva do possível é uma condição de realidade que determina a submissão dos direitos fundamentais aos recursos existentes. ${ }^{68}$

Contudo, não nos parece ser defensável que o impacto suscitado aos direitos sociais pela reserva do possível venha afetar intrinsecamente o conteúdo destes direitos ao escapar, dessa forma, do controle jurisdicional sobre os efeitos da reserva do possível

64 LOPES, José Reinaldo de Lima. Em torno da "reserva do possível". In: SARLET, Ingo Wolfgang; TIMM, Luciano Benetti (Org.). Direitos Fundamentais: orçamento e "reserva do possível". Porto Alegre: Livraria do Advogado, 2008. p. 180-181.

65 SARLET, Ingo Wolfgang; FIGUEIREDO, Mariana Filchtiner. Reserva do Possível, mínimo existencial e direito à saúde: algumas aproximações. In: SARLET, Ingo Wolfgang; TIMM, Luciano Benetti (Org.). Direitos Fundamentais: orçamento e "reserva do possível". Porto Alegre: Livraria do Advogado, 2008. p. 28.

66 O conceito surgiu na Alemanha por ocasião de uma decisão Tribunal Constitucional Federal (BVerfGE n. 33, 303 (333), no julgamento do famoso caso numerus clausus, em que se pleiteava o ingresso no ensino superior público, embora não existissem vagas suficientes, com base na Lei Federal alemã de liberdade de escolha de profissão. Como resultado, estabeleceu-se que o interessado somente poderia exigir uma prestação positiva do Estado dentro dos limites do razoável. Sobre o tema, conferir: TORRES, Ricardo Lobo. O mínimo existencial, os direitos sociais e os desafios de natureza orçamentária. In: SARLET, Ingo Wolfgang; TIMM, Luciano Benetti (Org.). Direitos Fundamentais: orçamento e "reserva do possível". Porto Alegre: Livraria do Advogado, 2008. p. 69-86; AMARAL, Gustavo; MELO, Danielle. Há direitos acima dos orçamentos? In: SARLET, Ingo Wolfgang; TIMM, Luciano Benetti (Org.). Direitos Fundamentais: orçamento e "reserva do possível". Porto Alegre: Livraria do Advogado, 2008. p. 87-109; SAMPAIO, Jorge Silva. O controle jurisdicional das políticas públicas de direitos sociais. Coimbra: Coimbra Editora, 2014. p. 272-301; LIBERATI, Wilson Donizeti. Políticas públicas no Estado Constitucional. São Paulo: Atlas, 2013. p. 116-121; GRINOVER, Ada Pellegrini. O controle jurisdicional de políticas públicas. In: GRINOVER, Ada Pellegrini; WATANABE, Kazuo (Coord.). O controle jurisdicional de políticas públicas. 2. ed. Rio de Janeiro: Forense, 2013. p. 138-139; CANELA JÚNIOR, Osvaldo. O orçamento e a "reserva do possível": dimensionamento no controle judicial de políticas públicas. In: GRINOVER, Ada Pellegrini; WATANABE, Kazuo (Coord.). O controle jurisdicional de políticas públicas. 2. ed. Rio de Janeiro: Forense, 2013. p. 231-233; CAMBI, Eduardo. Neoconstitucionalismo e neoprocessualismo: direitos fundamentais, políticas públicas e protagonismo judiciário. 2. ed. rev. e atual. São Paulo: RT, 2011. p. 367-488.

67 LIBERATI, Wilson Donizeti. Políticas públicas no Estado Constitucional. São Paulo: Atlas, 2013. p. 118.

68 OLSEN, Ana Carolina Lopes. Direitos fundamentais sociais: efetividade frente à reserva do possível. Curitiba: Juruá, 2009. p. 212. 
quando afinal, ainda que numa menor medida, tal justificação possa e deva ser controlada pelo juiz. ${ }^{69}$

A ideia de estabilidade e de inação (inércia), carga ideológica flagrantemente extraída da teoria da reserva do possível, é característico do Estado Liberal. Não se coaduna, nesta perspectiva, com os ideais de programação e de intervenção estatal, ínsitos ao Estado Social. Se constata a insuficiência de recursos para a consecução dos fins do Estado Social não deve paralisar sua atuação, mas inicia a programação, no tempo, dos elementos de arrecadação e otimiza os gastos futuros mediante a aplicação do princípio da proporcionalidade na distribuição dos recursos. ${ }^{70}$

Entende-se, pois, na trilha do que pontifica Vidal Serrano Nunes Júnior, que a teoria da reserva do possível, visto ter sido importada da Alemanha, só teria aplicação na ordem jurídica brasileira, nas hipóteses em que os direitos sociais estivessem alicerçados em comandos similares aos da Alemanha (onde a Constituição não hospedou expressamente aqueles direitos), porquanto a Constituição brasileira promoveu a fundamentalização formal dos direitos sociais. Ademais, a dignidade humana ao constituir um princípio ou valor absoluto por se assentar na premissa de que o ser humano é um fim e não meio, abarca aquele mínimo irremissível inerente a qualquer direito fundamental, inclusive os direitos sociais. Ademais, consubstancia a exigência de prestações do Estado que afiancem os pressupostos materiais mínimos para a preservação da vida e a inclusão na sociedade. Logo, não seria possível relativizar a noção de dignidade com base em previsões orçamentárias. ${ }^{71}$

\section{CONCLUSÃO}

Os direitos fundamentais (incluídos os direitos sociais), a partir da sua consagração jurídico-constitucional, apresentam-se como fundamento das políticas públicas de desenvolvimento e interessa-se pela visão que enquadra os direitos sociais como marco de ação das políticas públicas. Assim sendo, a natureza constitucional dos direitos sociais esparge a sua força ao contribuir decisivamente para a forma como as políticas públicas são implementadas, que são o mais importante dos instrumentos de operacionalização dos deveres positivos de direitos fundamentais, ou seja, é por meio das políticas públicas que o Estado concretiza os direitos fundamentais e, desse modo, protege, garante e promove o acesso individual aos bens jusfundamentais.

\footnotetext{
69 No mesmo sentido: SAMPAIO, Jorge Silva. O controle jurisdicional das políticas públicas de direitos sociais. Coimbra: Coimbra Editora, 2014. p. 294.

70 CANELA JÚNIOR, Osvaldo. Orçamento e a "reserva do possível": dimensionamento no controle judicial de políticas públicas. In: GRINOVER, Ada Pellegrini; WATANABE, Kazuo (Coord.). O controle jurisdicional de políticas públicas. 2. ed. Rio de Janeiro: Forense, 2013. p. 232-233.

71 NUNES JÚNIOR, Vidal Serrano. A cidadania social na Constituição de 1988: estratégias de positivação e exigibilidade judicial dos direitos sociais. São Paulo: Editora Verbatim, 2009. p. 114, 190.
} 
O Estado assume um duplo dever no âmbito dos direitos sociais que se traduz na consecução de políticas públicas de direitos sociais que serão corporizadas tanto por atuações normativas, como a aprovação de leis como por atuações fáticas, ligadas normalmente à execução dessas leis. Por um lado, o Estado está jurídico-constitucionalmente vinculado a um dever de proteção dos direitos fundamentais e, por outro, a um dever de promoção, realização desses mesmos direitos. A consecução estatal desses deveres corporiza normativamente as políticas públicas de direitos sociais.

Para além de incorporar os direitos fundamentais como marco conceitual explícito de políticas públicas sociais e de reconhecer que estes impõem certos limites à ação estatal, as políticas com enfoque de direitos enfrentam a magna tarefa de reconhecer e defrontar a pobreza, a vulnerabilidade e a exclusão social, fenômenos contrários aos direitos fundamentais e, em concreto, procurar tudo fazer para superar situações de inércia estatal para que, pelo menos, se cumpra o dever constitucional de garantir a todas as pessoas um nível de vida adequado. Tais situações de penúria social são inadmissíveis num Estado Social de Direito.

Que as políticas públicas, nos Estados Constitucionais em desenvolvimento, agem como instrumentos de consagração da cidadania, com a garantia jurídica dos direitos fundamentais sociais e que a permissão do ativismo judicial, já que o Poder Judiciário poderá exercer o controle das políticas públicas, não significa uma mera substituição das funções dos Poderes Legislativo e Executivo, mas, sobretudo, implica não deixar a pessoa humana desprovida do exercício de um direito fundamental, reconhecido na Constituição ou na lei, porque o Poder Público foi inerte.

Compete ao Poder Judiciário velar pela integridade dos direitos fundamentais, repelir condutas governamentais abusivas, conferir prevalência à dignidade da pessoa humana, fazer cumprir as normas que protegem os grupos mais vulneráveis e neutralizar todo e qualquer ensaio de opressão estatal. A prática da jurisdição, para a efetivação da Constituição, não é interferência indevida do Judiciário na esfera dos demais poderes da República. Não é censurável o protagonismo judiciário quando, diante da inércia e da omissão estatais, a sociedade exige posicionamento jurisprudencial criativo e positivo, para que se faça prevalecer a primazia da Constituição.

É preciso pensar a discricionariedade pautada nos fins constitucionais ao vincular a atuação do administrador em favor ou defesa dos direitos fundamentais e ao dever da boa administração. Nessa esteira, não há mais espaço para compreender a discricionariedade como um pretexto para decisões ineficientes, sejam as que não atendam ao interesse público implícito na finalidade legal, sejam as que o atendam de maneira deficiente.

A reserva do possível não deve ser concebida como um obstáculo instransponível para a efetivação dos direitos fundamentais. Deve ser conceituada como postulado capaz de otimizar a eficácia e efetividade desses direitos, a fim de que o Estado 
promova, da melhor maneira e de modo progressivo, a máxima realização dos direitos fundamentais.

\section{REFERÊNCIAS}

ABRAMOVICH, Víctor. El rol de la justicia en la articulación de politicas y derechos sociales. ABRAMOVICH, Víctor; PAUTASSI, Laura (Org.). La revisión de las políticas sociales: estudio de casos. Buenos Aires: Editores del Puerto, 2009. p. 1-91.

AMARAL, Gustavo; MELO, Danielle. Há direitos acima dos orçamentos? In: SARLET, Ingo Wolfgang; TIMM, Luciano Benetti (Org.). Direitos Fundamentais: orçamento e "reserva do possível". Porto Alegre: Livraria do Advogado, 2008. p. 87-109.

BARCELLOS, Ana Paula de. Constitucionalização das políticas públicas em matéria de direitos fundamentais: o controle político-social e o controle jurídico no espaço democrático. In: SARLET, Ingo Wolfgang; TIMM, Luciano Benetti (Org.). Direitos fundamentais: orçamento e "reserva do possível. Porto Alegre: Livraria do Advogado, 2008. p. 111-147.

BUCCI, Maria Paula Dallari. Direito administrativo e políticas públicas. São Paulo: Saraiva, 2002.

CANELA JÚNIOR, Osvaldo. Orçamento e a "reserva do possível": dimensionamento no controle judicial de políticas públicas. In: GRINOVER, Ada Pellegrini; WATANABE, Kazuo (Coord.). 0 controle jurisdicional de políticas públicas. 2. ed. Rio de Janeiro: Forense, 2013. p. 225-236.

CANOTILHO, José Joaquim Gomes. Direito Constitucional e teoria da constituição. 7. ed. Coimbra: Almedina, 2003.

CARBONELL, Miguel. Los derechos sociales: elementos para una lectura en clave normativa. In: MONTEROS, Javier Espinoza de los; ORDÓÑEZ, Jorge. Los derechos sociales en el Estado Constitucional. Valencia, ES: Tirant lo Blanch, 2013. p. 199-231.

CASTILHO, Ricardo. Justiça social e distributiva: desafios para concretizar direitos sociais. São Paulo: Saraiva, 2009.

DANIEL, Juliana Maia. Discricionariedade administrativa em matéria de políticas públicas. In: GRINOVER, Ada Pellegrini; WATANABE, Kazuo (Coord.). O controle jurisdicional de políticas públicas. 2. ed. Rio de Janeiro: Forense, 2013. p. 93-124.

DI PIETRO, Maria Sylvia Zanella. Direito Administrativo. 31. ed. rev. atual. e ampl. Rio de Janeiro: Forense, 2018.

FERRARY, Regina Maria Macedo Nery. Normas constitucionais programáticas: normatividade, operatividade e efetividade. São Paulo: RT, 2001.

FREITAS, Juarez. O controle dos atos administrativos e os princípios fundamentais. 4. ed. São Paulo: Malheiros, 2009. 
GALDINO, Flávio. O custo dos direitos. In: TORRES, Ricardo Lobo (Org.). Legitimação dos direitos humanos. Rio de Janeiro: Renovar, 2002. p. 139-222.

GARCÍA-PELAYO, Manuel. As transformações do Estado contemporâneo. Tradução de Agassiz Almeida Filho. Rio de Janeiro: Forense, 2009.

GAVARA DE CARA, Juan Carlos. La dimensión objetiva de los derechos sociales. Barcelona: Bosch, 2010.

GIMÉNEZ, Teresa Vicente. La exigibilidad de los derechos sociales. València: Tirant lo Blanch, 2006.

GRINOVER, Ada Pellegrini. O controle jurisdicional de políticas públicas. In: GRINOVER, Ada Pellegrini; WATANABE, Kazuo (Coord.). O controle jurisdicional de políticas públicas. 2. ed. Rio de Janeiro: Forense, 2013. p. 125-150.

KING, Jeff. Judging social rights. Cambridge, UK: Cambridge University Press, 2012.

LIBERATI, Wilson Donizeti. Políticas públicas no Estado Constitucional. São Paulo: Atlas, 2013.

LUÑO, Antonio Enrique Pérez. Derechos humanos, Estado de Derecho y Constitución. 9. ed. Madrid: Tecnos, 2005.

MEDAUAR, Odete. Controle da administração pública. 3. ed. rev. atual. e ampl. São Paulo: RT, 2014.

MEIRELES, Ana Cristina Costa. A eficácia dos direitos sociais. Salvador: Juspodivm, 2008.

MELLO, Celso Antônio Bandeira de. Discricionariedade e controle jurisdicional. 2. ed. São Paulo: Malheiros, 2010.

MORAIS, Carlos Blanco de. Curso de Direito Constitucional: teoria da Constituição em tempo de crise do Estado Social. Coimbra: Coimbra Editora, 2014. Tomo II. v. 2.

MOREIRA NETO, Diogo de Figueiredo. Quatro paradigmas do Direito Administrativo pós-moderno: legitimidade, finalidade, eficiência, resultados. Belo Horizonte: Fórum, 2008.

MURCIA, Luis Eduardo Pérez. Desarrollo, derechos sociales y políticas públicas. In: MURCIA, Luis Eduardo Pérez; YEPES, Rodrigo Uprimny; GARAVITO, César Rodríguez (Org.). Los derechos sociales en serio: hacia un diálogo entre derechos y políticas públicas. Bogotá: DeJuSticia, 2007. p. 72-129.

NOVAIS, Jorge Reis. Os princípios constitucionais estruturantes da república portuguesa. Coimbra: Coimbra Editora, 2004.

NOVAIS, Jorge Reis. Direitos sociais: teoria jurídica dos direitos sociais enquanto direitos fundamentais. Coimbra: Coimbra Editora, 2010.

NUNES JÚNIOR, Vidal Serrano. A cidadania social na Constituição de 1988: estratégias de positivação e exigibilidade judicial dos direitos sociais. São Paulo: Editora Verbatim, 2009. p. 114, 190. 
OLSEN, Ana Carolina Lopes. Direitos fundamentais sociais: efetividade frente à reserva do possível. Curitiba: Juruá, 2009.

OTERO, Paulo. Direito constitucional português: identidade constitucional. Coimbra: Almedina, 2010. v. 1.

RADBRUCH, Gustav. Introducción a la filosofía del derecho. Tradução de Wenceslao Roces. Ciudad de México: Fondo de Cultura Económica, 1955. p. 162.

SAMPAIO, Jorge Silva. $\mathbf{O}$ controle jurisdicional das políticas públicas de direitos sociais. Coimbra: Coimbra Editora, 2014.

SANCHÍS, Luis Prieto. Justicia constitucional y derechos fundamentales. Madrid: Trotta, 2003.

SARDÀ, Clara Marquet. Los derechos sociales en el ordenamiento jurídico sueco: estudio de una categoría normativa. Barcelona: Atelier, 2010.

SARLET, Ingo Wolfgang; FIGUEIREDO, Mariana Filchtiner. Reserva do Possível, mínimo existencial e direito à saúde: algumas aproximações. In: SARLET, Ingo Wolfgang; TIMM, Luciano Benetti (Org.). Direitos Fundamentais: orçamento e "reserva do possível". Porto Alegre: Livraria do Advogado, 2008. p. 11-53.

SARLET, Ingo Wolfgang. A eficácia dos direitos fundamentais: uma teoria geral dos direitos fundamentais na perspectiva constitucional. 12. ed. rev. atual. e ampl. Porto Alegre: Livraria do Advogado, 2015.

TORRES, Ricardo Lobo. O mínimo existencial, os direitos sociais e os desafios de natureza orçamentária. In: SARLET, Ingo Wolfgang; TIMM, Luciano Benetti (Org.). Direitos Fundamentais: orçamento e "reserva do possível". Porto Alegre: Livraria do Advogado, 2008. p. 69-86. 